\title{
Theme Trends and Knowledge Structure on Mobile Health Apps: Bibliometric Analysis
}

Cheng Peng ${ }^{1}$, MD, PhD; Miao He², BSc; Sarah L Cutrona ${ }^{3,4}$, MD, MPH; Catarina I Kiefe ${ }^{3}$, MD, PhD; Feifan Liu ${ }^{3}$, $\mathrm{PhD}$; Zhongqing Wang ${ }^{2,3}$, BSc, MBA

\footnotetext{
${ }^{1}$ Department of Ophthalmology, The Fourth Affiliated Hospital of China Medical University, Shenyang, China

${ }^{2}$ Department of Information Center, The First Hospital of China Medical University, Shenyang, China

${ }^{3}$ Department of Population and Quantitative Health Sciences, University of Massachusetts Medical School, Worcester, MA, United States

${ }^{4}$ Center for Healthcare Organization and Implementation Research, Edith Nourse Rogers Memorial Veterans Hospital, Bedford, MA, United States
}

\section{Corresponding Author:}

Zhongqing Wang, BSc, MBA

Department of Information Center

The First Hospital of China Medical University

155 Nanjinbei Street

Shenyang

China

Phone: 8615940082159

Email: wangzhongqing@cmu.edu.cn

\section{Abstract}

Background: Due to the widespread and unprecedented popularity of mobile phones, the use of digital medicine and mobile health apps has seen significant growth. Mobile health apps have tremendous potential for monitoring and treating diseases, improving patient care, and promoting health.

Objective: This paper aims to explore research trends, coauthorship networks, and the research hot spots of mobile health app research.

Methods: Publications related to mobile health apps were retrieved and extracted from the Web of Science database with no language restrictions. Bibliographic Item Co-Occurrence Matrix Builder was employed to extract bibliographic information (publication year and journal source) and perform a descriptive analysis. We then used the VOSviewer (Leiden University) tool to construct and visualize the co-occurrence networks of researchers, research institutions, countries/regions, citations, and keywords.

Results: We retrieved 2802 research papers on mobile health apps published from 2000 to 2019. The number of annual publications increased over the past 19 years. JMIR mHealth and uHealth (323/2802, 11.53\%), Journal of Medical Internet Research (106/2802, 3.78\%), and JMIR Research Protocols (82/2802, 2.93\%) were the most common journals for these publications. The United States (1186/2802, 42.33\%), England (235/2802, 8.39\%), Australia (215/2802, 7.67\%), and Canada (112/2802, 4.00\%) were the most productive countries of origin. The University of California San Francisco, the University of Washington, and the University of Toronto were the most productive institutions. As for the authors' contributions, Schnall R, Kuhn E, Lopez-Coronado M, and Kim J were the most active researchers. The co-occurrence cluster analysis of the top 100 keywords forms 5 clusters: (1) the technology and system development of mobile health apps; (2) mobile health apps for mental health; (3) mobile health apps in telemedicine, chronic disease, and medication adherence management; (4) mobile health apps in health behavior and health promotion; and (5) mobile health apps in disease prevention via the internet.

Conclusions: We summarize the recent advances in mobile health app research and shed light on their research frontier, trends, and hot topics through bibliometric analysis and network visualization. These findings may provide valuable guidance on future research directions and perspectives in this rapidly developing field.

(JMIR Mhealth Uhealth 2020;8(7):e18212) doi: $\underline{10.2196 / 18212}$

\section{KEYWORDS}

mobile app; mobile health; mhealth; digital health; digital medicine; bibliometrics; co-word analysis; mobile phone; VOSviewer 


\section{Introduction}

Worldwide, the use of mobile phones has reached widespread popularity at an unprecedented rate [1]. There were more than 325,000 mobile health apps in 2017 [2]. According to Zion Market Research, the global mobile health app market will grow from $\$ 8.0$ billion in 2018 to $\$ 111.1$ billion by 2025 [3]. Recently, mobile health apps have seen significant growth. An increasing number of hospitals and health care institutions are using mobile health apps to monitor the development of diseases and improve health care outcomes [4]. Therefore, it is essential to understand the use, significance, trends, and research hot spots of mobile health apps in the health care domain.

Bibliometric analysis has been widely used in quantitative analysis of academic literature to describe the hot spots, trends, and contributions of scholars, journals, and countries/regions [5-8]. Co-word analysis, proposed in the late 1970s [9,10] as an important bibliometric technique, can identify the main themes, investigate hot spots, and detect knowledge in literature. Thus, bibliometrics can contribute to monitoring the development and patterns of effective publications [11]. In recent years, bibliometric analysis has been applied to biomedicine and health care [12-15]. In the current study, we used bibliometric quantitative analysis and network visualization to describe the research trends, research hot spots, emerging topics, and collaboration partners in the field of mobile health apps. Our study is the first one to quantitatively analyze the characteristics and hot topics of mobile health app research. Our study may provide valuable guidance on future research directions in this rapidly developing field.

\section{Methods}

\section{Data Collection}

Web of Science (WOS) is an extensive international database of academic information, including more than 9000 prestigious and high-impact research journals from all over the world. WOS contains various characteristics that can be used for bibliometric study, including title, author, institution, country/region, publication year, and keywords [9]. WOS has been recently receiving more attention as a reliable data source for bibliometric analysis in the biomedical domain, with applications in clinical and bench science research questions (eg, cardiovascular disease, diabetic kidney disease, and long noncoding RNA) $[8,16,17]$. On October 6, 2019, we conducted a publication search in WOS to find publications using the following search strategy: TS="mobile health app*" OR (TS="mobile app*" AND $\mathrm{TS}=$ ("health*" OR "medic*" OR "clinic*" OR "hospital*”)). Only full-length papers were included, and no language limitation was set. We validated the reliability of our search strategy by manually reviewing the retrieved publications [18]. All data from retrieved publications were collected and saved in TXT formats.

\section{Data Analysis and Visualization Maps}

We aimed to exploit bibliometric analysis to identify the knowledge structure, research frontiers, research hot spots, active authors, and other bibliometric information in the mobile health app area. Bibliometric analysis typically consists of the construction of bibliometric maps and the graphical representation of such maps [19]. Co-word analysis was used to calculate the frequency of co-occurrence of bibliographic information and perform hierarchical clustering based on the co-occurrence information $[9,10]$. Finally, the clusters were visualized graphically.

In this study, we have applied widely used bibliometric analysis tools on the WOS data. Bibliographic Item Co-Occurrence Matrix Builder version 2.0 [10] was used to extract and analyze bibliographic information on the publication years and the journal sources. VOSviewer (version 1.6.13; Leiden University) was used to extract bibliographic information on researchers, institutions, countries/regions, references, and keywords. VOSviewer uses the visualization of similarities mapping technique, which produces better structured maps than other popular multidimensional scaling techniques for bibliometrics [19]. Specifically, when constructing a map, VOSviewer takes as input a similarity matrix that is created using a similarity measure known as the association strength [20]. It calculates the similarity $s_{i j}$ of two items $i$ and $j$ with the equation $s_{i j}=c_{i j}$ / $\left(w_{i} w_{j}\right)$, where $c_{i j}$ denotes the number of co-occurrences of items $i$ and $j$, and where $w_{i}$ and $w_{j}$ denote the total number of occurrences of items $i$ and $j$. Once the similarity matrix is created, VOSviewer maps all the items in a 2-dimensional map so that items with a high similarity will be located close to each other, while items with a low similarity will be located far from each other. Unlike other map-viewing programs, VOSviewer pays special attention to the graphical representation of bibliometric maps in an easy-to-interpret way [19].

Using network-mapping techniques, we created different bibliometric maps that included coauthorships of authors, institutions, and countries/regions; co-citations of references; and co-occurrence of keywords. Each node in a map is represented by a circle with a label. Larger circles indicate higher-frequency items. The color of each circle is determined by the clusters it belongs to. The thickness and length of links between nodes represent the association strength between corresponding nodes. A maximum of 500 lines was set to display the 500 strongest links between nodes.

\section{Research Ethics}

Data from bibliographic information were searched and downloaded from WOS. These were publicly available data. The extraction of these data did not involve interaction with human subjects or animals. Thus, there were no ethical issues involving the use of these data, and no approval from an ethics committee was required.

\section{Results}

\section{Publication Outputs}

Based on our search strategy, we identified and incorporated 2802 publications on mobile health apps from WOS. The number of annual publications on mobile health apps increased from 2 publications in 2000 to 692 publications in 2018 (2019 data are incomplete because they reflect only approximately 9 months of publications). Before 2013, the number of annual 
publications did not exceed 100 . However, the number of annual publications in 2014, 2015, 2016, 2017, and 2018 was 122, 263, 430,507 , and 692, respectively.

\section{Distribution of Source Journals}

Publications on mobile health app research were distributed across 1209 journals; 848 of these journals have published only
1 paper on mobile health apps. Table 1 lists the top 10 journals on this topic. JMIR mHealth and uHealth published the most papers $(323 / 2802,11.53 \%)$, followed by Journal of Medical Internet Research (106/2802, 3.78\%), then JMIR Research Protocols $(82 / 2802,2.93 \%)$. The top 10 journals published 776 publications, accounting for $27.64 \%$ of all publications in this study.

Table 1. Top 10 journals publishing research on mobile health app research, 2000-2019.

\begin{tabular}{|c|c|c|c|c|c|}
\hline Rank & Journal & Country & Categories & Publications, $\mathrm{n}$ & Percentage $^{\mathrm{a}}$ \\
\hline 1 & JMIR mHealth and uHealth & Canada & Medical informatics & 323 & 11.53 \\
\hline 2 & Journal of Medical Internet Research & Canada & Medical informatics & 106 & 3.78 \\
\hline 3 & JMIR Research Protocols & Canada & Medical informatics & 82 & 2.93 \\
\hline 4 & Plos One & United States & Multidisciplinary sciences & 47 & 1.68 \\
\hline 5 & Journal of Medical Systems & United States & Medical informatics & 43 & 1.53 \\
\hline 6 & $\begin{array}{l}\text { BMC Medical Informatics and Decision } \\
\text { Making }\end{array}$ & England & Medical informatics & 37 & 1.32 \\
\hline 7 & International Journal of Medical Informatics & Ireland & Medical informatics & 37 & 1.32 \\
\hline 8 & Telemedicine and e-Health & United States & Health care sciences and services & 37 & 1.32 \\
\hline 9 & JMIR Mental Health & Canada & Medical informatics and mental health & 33 & 1.18 \\
\hline 10 & BMJ Open & England & Medicine, general and internal & 31 & 1.11 \\
\hline
\end{tabular}

${ }^{\mathrm{a}}$ The total number of retrieved papers on mobile health apps from 2000 to $2019(\mathrm{~N}=2802)$ was used as the denominator.

\section{Distribution and Coauthorship of Countries/Regions}

According to the search results, 2802 publications came from 104 countries/regions. Figure 1 shows the location of the top 30 countries/regions that were publishing mobile health app research. The United States has the largest number of publications $(1186 / 2802,42.33 \%)$ and England ranks second $(235 / 2802,8.39 \%)$, followed by Australia $(215 / 2802,7.67 \%)$ and Canada $(112 / 2802,4.00 \%)$.

Figure 1. Top 30 countries/regions publishing mobile health app research, 2000-2019.

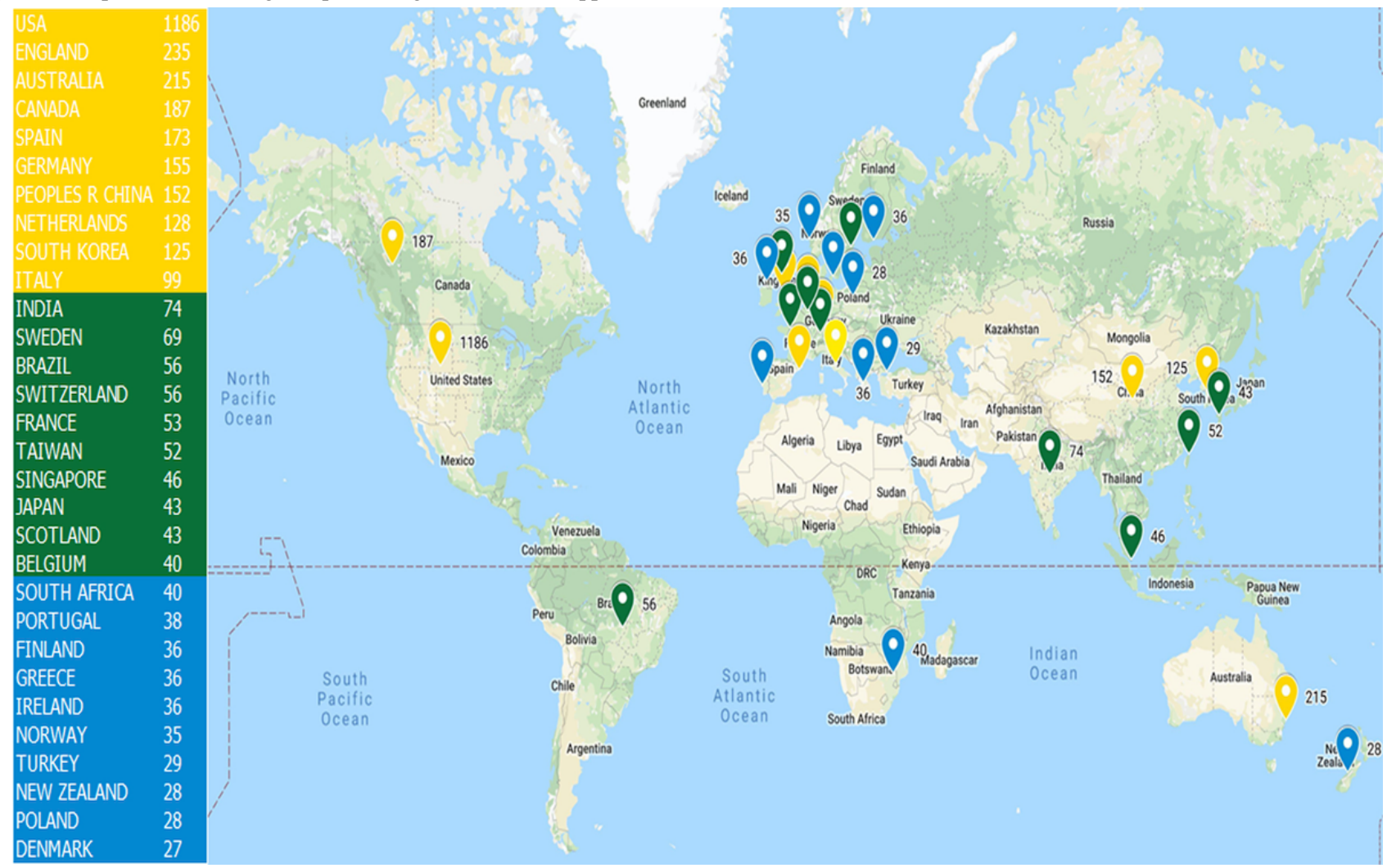


As shown in Figure 2, the coauthorship analysis of countries/regions reflects the collaboration relationship between countries/regions in this field, as well as the degree of collaboration. The larger nodes represent more productive countries/regions in this field; the thickness and length of links between nodes represent the cooperative relationship between countries/regions. Figure 2 shows the 45 most productive countries/regions in this field from 4 collaboration clusters, which were distinguished by different colors.

Figure 2. The coauthorship network of countries/regions that contributed to mobile health app research, 2000-2019. Peoples R China: People's Republic of China. USA: United States of America.

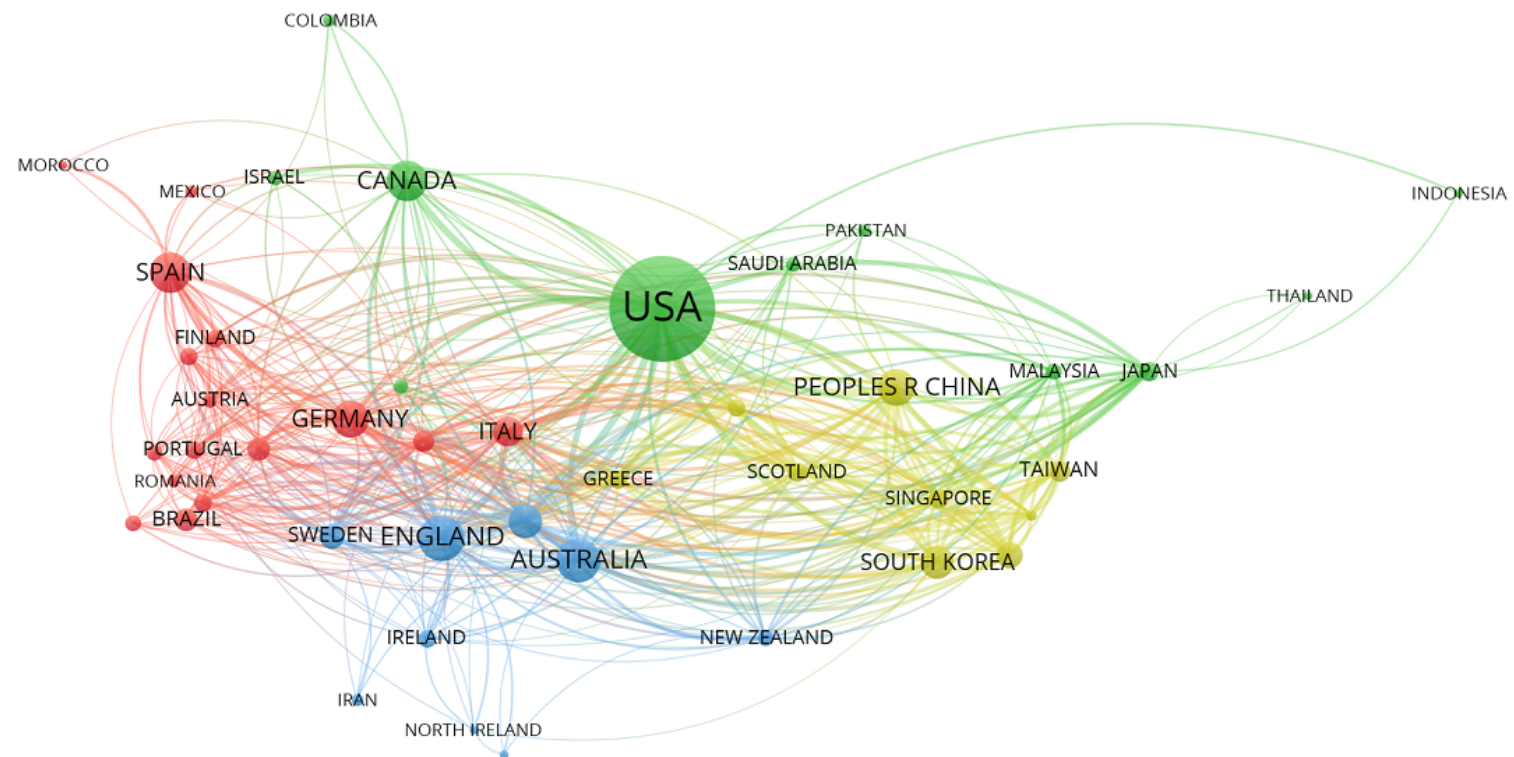

\section{Distribution and Coauthorship of Institutions}

According to the search results, 3795 research institutions contributed to mobile health app research. Table 2 presents the top 10 most productive institutions in mobile health app research. The University of California San Francisco (67 publications) ranked first among all institutions identified, followed by the University of Washington (58 publications) and the University of Toronto (56 publications).

Table 2. Top 10 most productive institutions in mobile health app research, 2000-2019.

\begin{tabular}{lllll}
\hline Rank & Institution & Country & Publications, $\mathrm{n}$ & Citations, $\mathrm{n}$ \\
\hline 1 & Univ ${ }^{\mathrm{a}}$ of California San Francisco & United States & 67 & 819 \\
2 & Univ of Washington & United States & 58 & 511 \\
3 & Univ of Toronto & Canada & 56 & 640 \\
4 & Stanford Univ & United States & 46 & 432 \\
5 & Univ of Pittsburgh & United States & 45 & 409 \\
6 & Harvard Medical School & United States & 42 & 388 \\
7 & Columbia Univ & United States & 39 & 387 \\
8 & Northwestern Univ & United States & 39 & 296 \\
10 & Univ of Sydney & Australia & 39 & 240 \\
\hline
\end{tabular}

${ }^{\mathrm{a}}$ Univ: university. 
Coauthorship analysis was performed by VOSviewer to display the visualization network map of institutions in mobile health app research. The link between institutions is determined by the number of publications coauthored between them. The coauthorship analysis of institutions shows that 99 institutions, each of which published at least 10 papers, formed 8 clusters. These clusters are shown in Figure 3 and distinguished by different colors.

Figure 3. The coauthorship network of institutions that contributed to mobile health app research, 2000-2019. Univ: university.

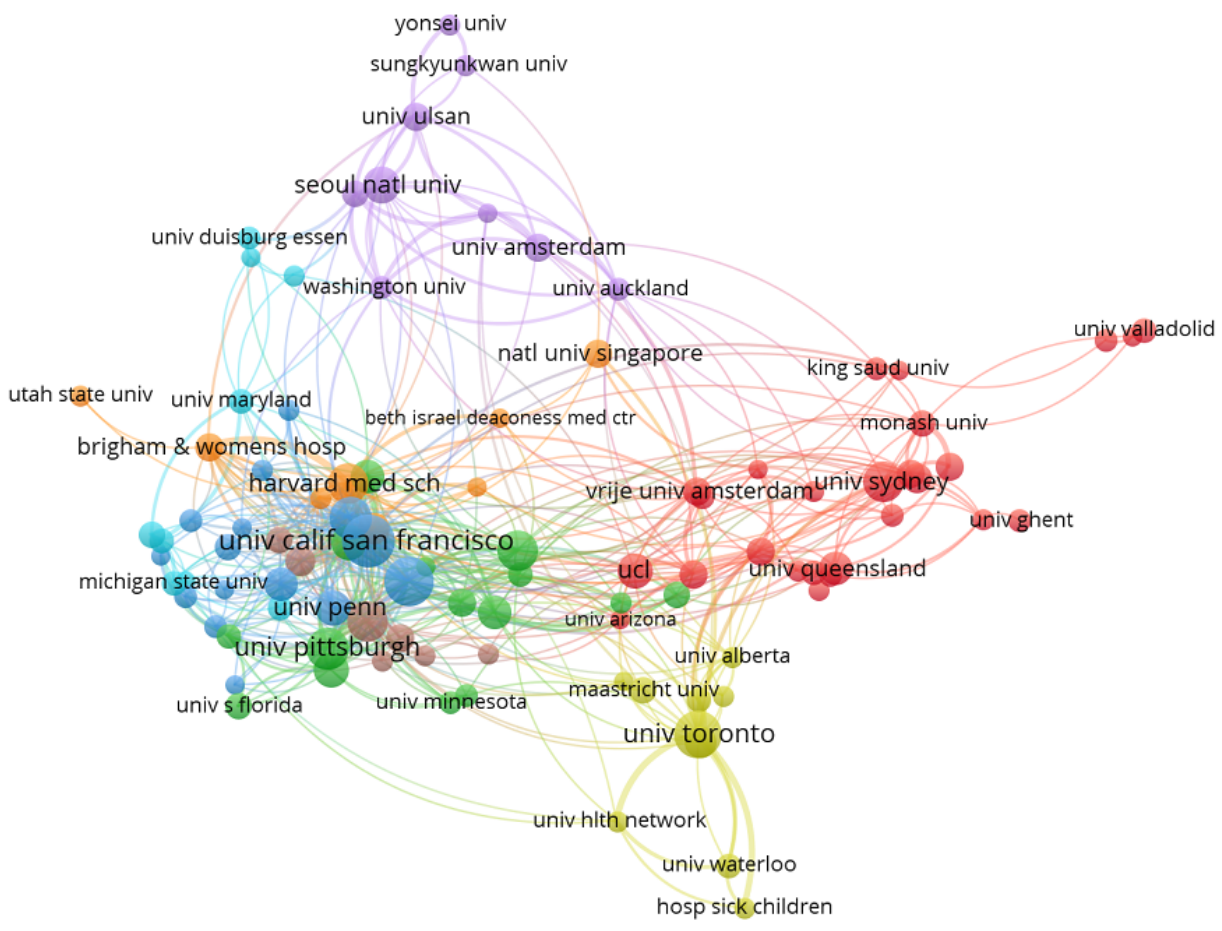

\section{Distribution and Coauthorship of Authors}

According to the search results, 2802 mobile health app publications were written by 13,040 authors, with an average of 5 authors per publication. Table 3 presents the top 10 most productive authors (all authors of each publication were ranked equally) in mobile health app research. Schnall $\mathrm{R}$ (15 publications) ranked first among all authors, followed by Kuhn E (14 publications), Lopez-Coronado M (14 publications), and Kim J (14 publications).

Table 3. Top 10 most productive authors in mobile health app research, 2000-2019.

\begin{tabular}{llll}
\hline Rank & Author & Publications, $\mathrm{n}$ & Citations, $\mathrm{n}$ \\
\hline 1 & Schnall R & 15 & 217 \\
2 & Kuhn E & 14 & 223 \\
3 & Lopez-Coronado M & 14 & 130 \\
4 & Kim J & 14 & 43 \\
5 & Lee S & 13 & 365 \\
6 & Li J & 13 & 49 \\
7 & Torous J & 12 & 271 \\
8 & Lee JH & 10 & 107 \\
9 & Lee J & 10 & 46 \\
10 & Zhang Y & 10 & 36 \\
\hline
\end{tabular}

Our coauthorship analysis of authors showed that 221 of 13,040 authors had published at least 4 papers, and the largest set of associated authors consisted of 95 authors in 6 clusters. The node label shows the author's name, and the node size represents the number of published publications. Links connecting 2 nodes represent coauthorship between the 2 authors, and thicker links represent more collaboration between the 2 authors, as shown in Figure 4. 
Figure 4. The coauthorship network of authors who contributed to mobile health app research, 2000-2019.

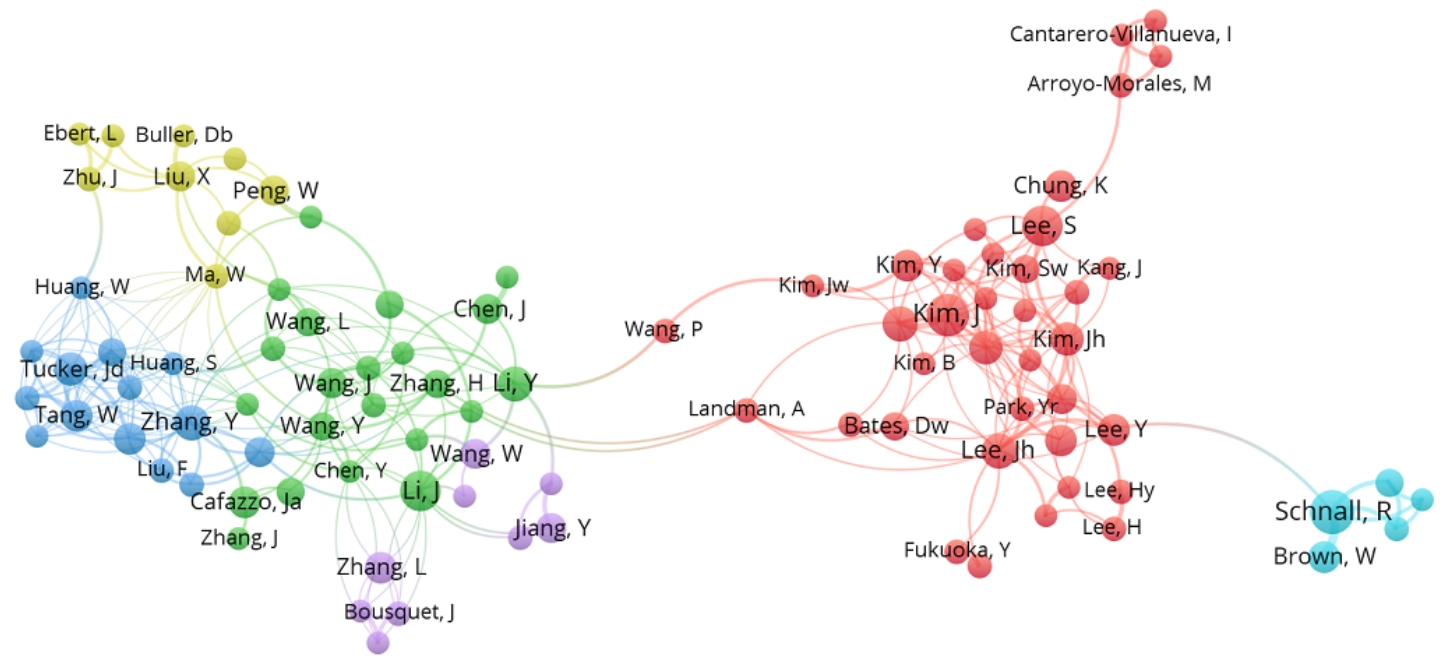

\section{Reference Co-Citation Analysis}

Through the co-citation analysis (examining references cited in publications), we explored the knowledge base for the mobile health apps field. We identified 2802 mobile health app publications, which cited 76,721 references, averaging 27 references per publication. The top 10 most frequently cited references are listed in Table 4. The publication that received the most citations, Stoyanov and colleagues' "Mobile App
Rating Scale: A New Tool for Assessing the Quality of Health Mobile Apps," was published in JMIR mHealth and uHealth in 2015 and received a total of 106 citations as of October 6, 2019. We chose the top 64 references, which were cited at least 30 times by the retrieved papers, to generate a visualization network map with VOSviewer of co-cited references in mobile health app research. This visualization network showed 3 main clusters marked in different colors, as shown in Figure 5. 
Table 4. Top 10 cited references in mobile health app research, 2000-2019.

\begin{tabular}{|c|c|c|c|c|}
\hline Rank & Author & Journal & Title & Citations, $\mathrm{n}$ \\
\hline 1 & Stoyanov SR et al (2015) & JMIR mHealth and uHealth & $\begin{array}{l}\text { Mobile App Rating Scale: A New Tool for Assessing the Quality } \\
\text { of Health Mobile Apps }\end{array}$ & 106 \\
\hline 2 & Free $\mathrm{C}$ et al (2013) & $\begin{array}{l}\text { Public Library of Science } \\
\text { Medicine }\end{array}$ & $\begin{array}{l}\text { The Effectiveness of Mobile-Health Technologies to Improve } \\
\text { Health Care Service Delivery Processes: A Systematic Review } \\
\text { and Meta-Analysis }\end{array}$ & 101 \\
\hline 3 & $\begin{array}{l}\text { Braun V and Clarke V } \\
\text { (2006) }\end{array}$ & $\begin{array}{l}\text { Qualitative Research in Psy- } \\
\text { chology }\end{array}$ & Using Thematic Analysis in Psychology & 98 \\
\hline 4 & Donker T et al (2013) & $\begin{array}{l}\text { Journal of Medical Internet } \\
\text { Research }\end{array}$ & $\begin{array}{l}\text { Smartphones for Smarter Delivery of Mental Health Programs: A } \\
\text { Systematic Review }\end{array}$ & 85 \\
\hline 5 & $\begin{array}{l}\text { Krebs P and Duncan } \\
\text { DT(2015) }\end{array}$ & JMIR mHealth and uHealth & $\begin{array}{l}\text { Health App Use Among US Mobile Phone Owners: A National } \\
\text { Survey }\end{array}$ & 79 \\
\hline 6 & Davis FD (1989) & $\begin{array}{l}\text { Management Information } \\
\text { Systems Quarterly }\end{array}$ & $\begin{array}{l}\text { Perceived Usefulness, Perceived Ease of Use, and User Acceptance } \\
\text { of Information Technology }\end{array}$ & 78 \\
\hline 7 & Dennison L et al (2013) & $\begin{array}{l}\text { Journal of Medical Internet } \\
\text { Research }\end{array}$ & $\begin{array}{l}\text { Opportunities and Challenges for Smartphone Applications in } \\
\text { Supporting Health Behavior Change: Qualitative Study }\end{array}$ & 77 \\
\hline 8 & Mosa AM et al (2012) & $\begin{array}{l}\text { BMC Medical Informatics } \\
\text { and Decision Making }\end{array}$ & A Systematic Review of Healthcare Applications for Smartphones & 71 \\
\hline 9 & Luxton DD et al (2011) & $\begin{array}{l}\text { Professional Psychology: Re- } \\
\text { search and Practice }\end{array}$ & $\begin{array}{l}\text { mHealth for Mental Health: Integrating Smartphone Technology } \\
\text { in Behavioral Healthcare }\end{array}$ & 58 \\
\hline 10 & Riley WT et al (2011) & $\begin{array}{l}\text { Translational Behavioral } \\
\text { Medicine }\end{array}$ & Health Behavior Models in the Age of Mobile Interventions & 58 \\
\hline
\end{tabular}

Figure 5. The co-citation network of references in mobile health app research, 2000-2019.

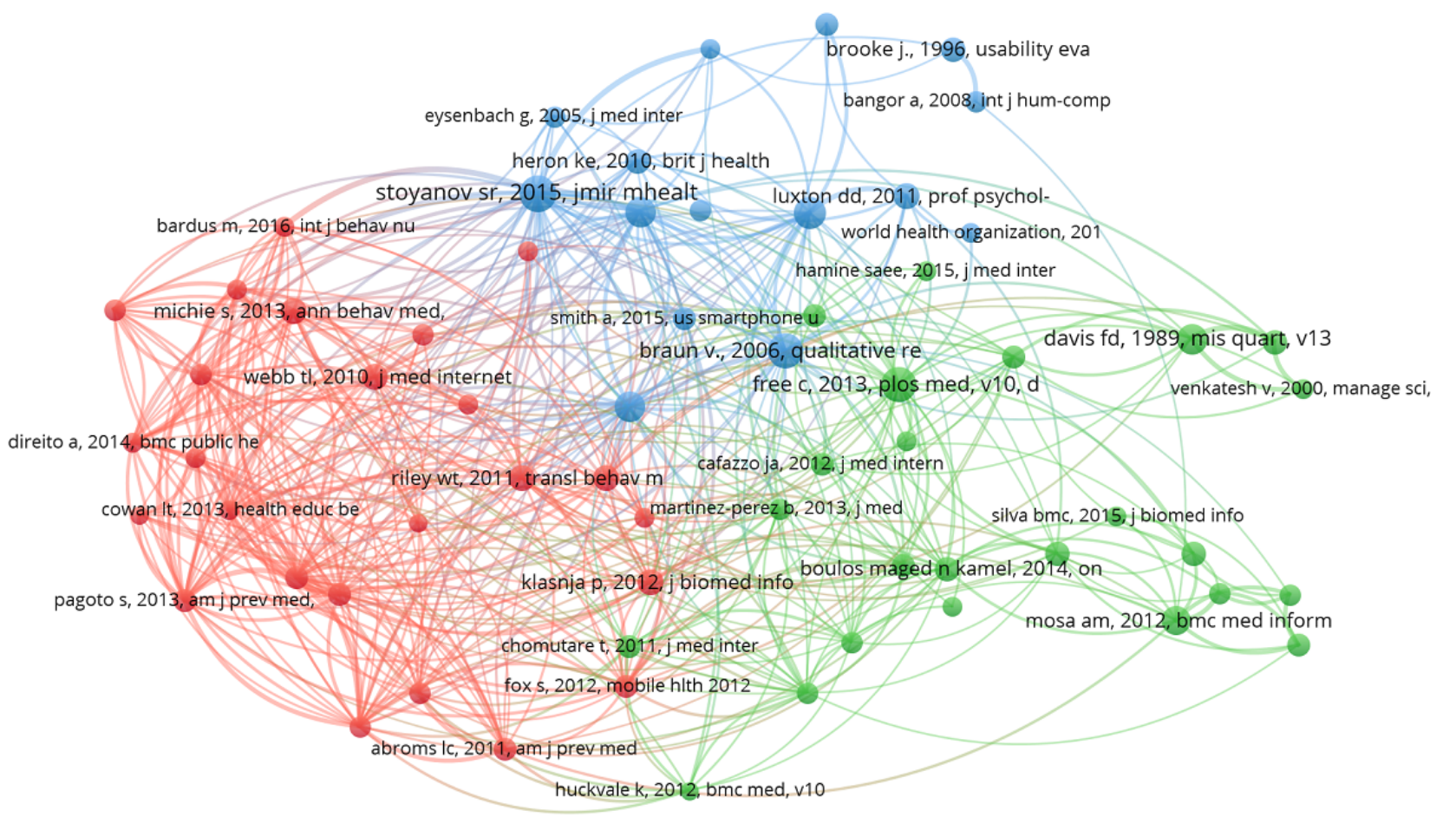

\section{Co-Occurrence Analysis of Top 100 Keywords}

Keywords cover the main topics of a publication and are well suited to be used for analyzing related research hot spots. The research hot spots of mobile health app research were identified through co-occurrence analysis of the top 100 keywords. We used VOSviewer to extract and cluster the top 100 keywords. Multimedia Appendix 1 shows the frequency and clustering of the top 100 keywords.

As shown in Figure 6, we used VOSviewer to build a visualization network map of the top 100 keywords in 5 clusters 
with their co-occurrence. The keywords mobile application (1124), mobile health (631), intervention (347), health (329), and technology (315) are located at the center of the visualization network map. The 5 clusters are represented by color: red (cluster 1), green (cluster 2), blue (cluster 3), yellow (cluster 4), and purple (cluster 5). The node label is the keyword, and the node size represents the frequency of the keywords. Links connecting 2 nodes represent a co-occurrence relationship between the keywords. For visualization purposes, the top 500 links among keywords were determined based on how frequently they co-occur in the same publication.

Figure 6. The co-occurrence network of the top 100 keywords in mobile health app research, 2000-2019.

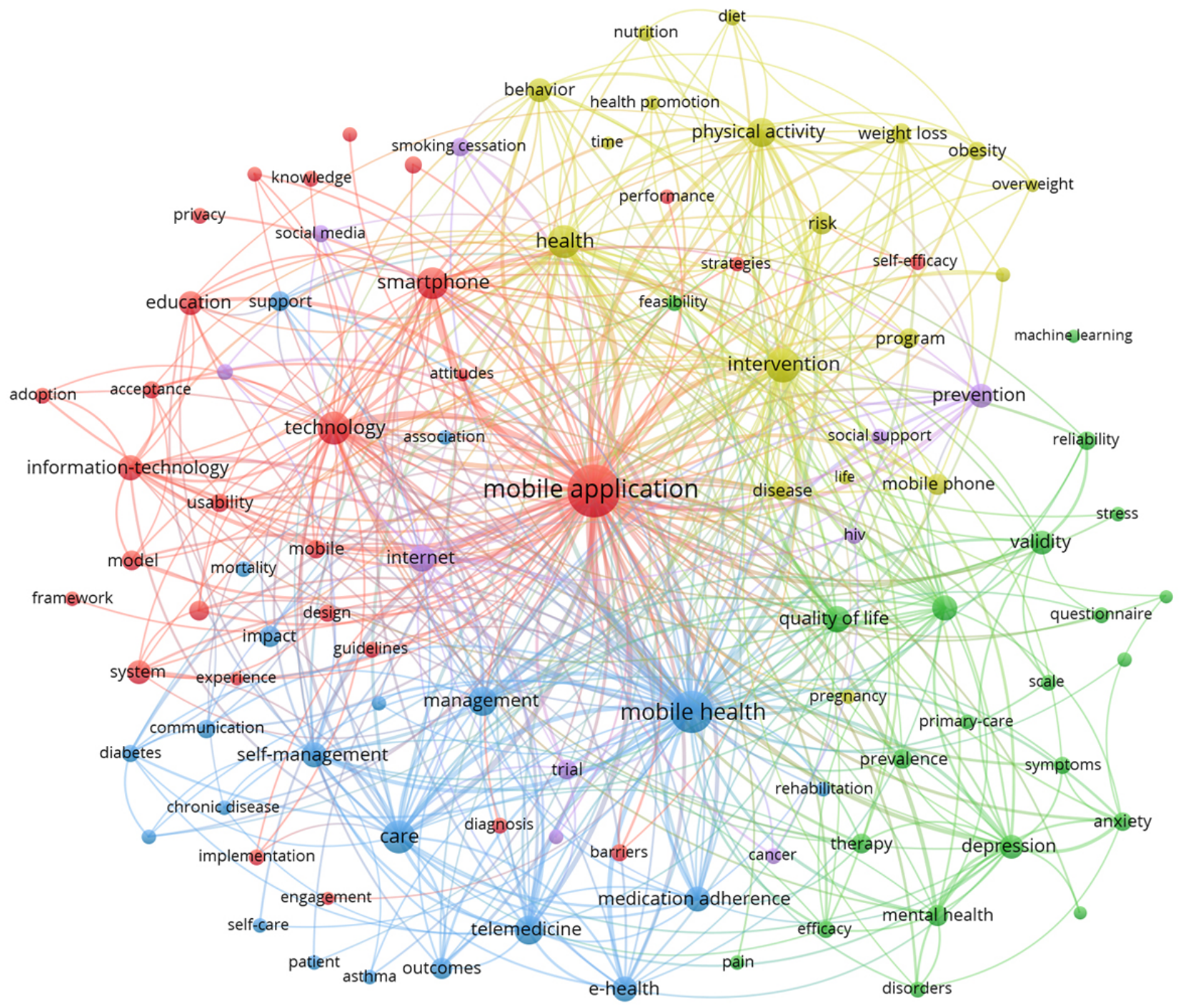

\section{Discussion}

In the current study, we explored the bibliometric characteristics of mobile health app research and we identified research trends, research hot spots, and the knowledge base associated with mobile health apps through our co-word analysis of the top 100 keywords.

\section{Global Trends in Mobile Health App Research}

The change in the number of academic publications in a field is an important indicator of the evolving trends in this field. Mobile health app research included over 2800 publications around the world. The number of research papers published on mobile health apps annually has been increasing since 2000, with particularly notable gains in the past 5 years.
For journal sources, the top 3 journals publishing mobile health app research belong to the area of medical informatics, accounting for $18.24 \%(511 / 2802)$ of the total publications. Meanwhile, 848 journals had only 1 mobile health app-related publication, accounting for $30.26 \%(848 / 2802)$ of the total publications. Journals publishing mobile health app research were widely distributed across the general health domain, with higher concentration, as expected, in the field of medical informatics.

\section{The Coauthorship Networks in Mobile Health App Research}

Due to the accessibility of bibliometric analysis, coauthorship is frequently used as a proxy for research collaboration. A coauthorship network can reflect the collaborative relationship among researchers and provide potential opportunities for other 
researchers to cooperate; examining this network can highlight potential opportunities for enhanced collaboration both within and outside of the existing network. The coauthorship network reflects author, institution, and country.

We found that the United States was the most significant contributor to mobile health app research. Of the publications identified, 65.06\% (1823/2802) were published in the United States, England, Australia, and Canada, the current global leaders in mobile health app research. Figure 2 shows that the United States is the center of an international coauthorship network and cooperates with many countries/regions. The yellow coauthorship networks are mainly Asian countries/regions, such as China, Korea, and Singapore. The blue coauthorship networks are dominated by European countries such as Germany, Spain, and Italy. Our findings indicate that cooperation among countries/regions has certain regional characteristics. These groupings prompt speculation that cooperation on mobile health app research among countries/regions may be influenced by geographic proximity or by a shared language.

We found that 7 of the top 10 most productive institutions are from the United States, and the other 3 are from Canada, Australia, and South Korea. Figure 3 shows that the top 10 institutions are almost at the core of each coauthorship network. These most productive institutions and groups are leading the trends in mobile health app research. There is an excellent cooperative relationship between these institutions.

We identified 13,040 authors who have published research on mobile health apps. Of those authors, only 233 (1.79\%) have published more than 4 papers in this emerging field, forming 5 relatively small coauthorship networks. We conclude from this finding that there are many researchers interested in pursuing mobile health app research, but collaboration between authors remains limited. Promoting collaboration between authors, institutions, and countries would expand the number of authors regularly publishing in this field and could contribute to more effective dissemination of innovative practices in mobile health app use.

\section{Basic Knowledge and Hot Topics in Mobile Health Apps}

More than three-quarters of the top 10 most frequently cited references in mobile health app research were published after 2011. This timeline is consistent with our understanding of mobile health app research as a rapidly emerging field of study. As shown in Figure 5, the most frequently cited references formed 3 clusters (shown in red, green, and blue). These clusters correspond to 3 basic groupings of research: (1) promotion of health behavior change (in red), (2) evaluation of quality of mobile health apps (in green), and (3) assessment of efficiency of mobile health apps (in blue).

Keywords are standardized terms used to ensure that publications are indexed uniformly by topic. Therefore, mapping the co-word network by analyzing the co-occurrence frequency of keywords from multiple publications is helpful to study the internal structure and the hot topics in the field of mobile health app research [21]. As shown in Figure 6, there were 5 clusters of mobile health app research that were formed by co-occurrence cluster analysis of the top 100 keywords. Combined with the characteristics of mobile health apps, the 5 clusters were analyzed as described below.

Cluster 1 (red cluster) mainly focuses on the technology and system development of mobile health apps and includes 29 high-frequency keywords, such as mobile app, technology, smartphone, system, model, usability, acceptance, design, devices, barriers, privacy, and attitudes. With the continuous development of smartphone and information technology, researchers need to update or develop new mobile health apps to meet the growing needs of patients and medical staff. The system development of mobile health apps mainly includes a user-computer interface, algorithms, privacy, design, and computer security, and it follows the principles of user-centered, convenient operation, safety, and stability [22,23]. As a new product, the effectiveness, quality, and accuracy of various mobile health apps used in health care need to be continuously evaluated through academic research [24,25].

Cluster 2 (green cluster) mainly focuses on mobile health apps used in mental health and includes 22 high-frequency keywords, such as quality of life, depression, validity, mental health, prevalence, therapy, anxiety, reliability, efficacy, disorders, questionnaire, stress, and cognitive behavioral therapy. It is reported that about $29 \%$ of humans suffer from mental illness in their lifetime, and more than $55 \%$ of these do not receive the treatment they need [26]. Mobile health apps can provide instant support, anonymity, customization, and low cost. These characteristics can potentially improve access to mental health services, thereby improving the equity of mental health resource allocation. Mobile health apps can be used as independent self-help mental health assessment tools and can be used to deliver online interventions aimed at diagnosis, treatment, and monitoring. Importantly, mobile health apps improve the accessibility of treatment through ecological momentary assessment to reduce the barriers to face-to-face help, especially in patients with depression, anxiety, stress, and other symptoms [27,28].

Cluster 3 (blue cluster) focuses on mobile health apps used as mobile health tools in telemedicine, chronic disease, and medication adherence management and includes 21 high-frequency keywords such as mobile health, care, telemedicine, self-management, eHealth, medication adherence, communication, diabetes, chronic disease, glycemic control, hypertension, and asthma. Telemedicine delivered using mobile health apps is an innovative model of health care, with significant potential to solve challenges in today's health care environment [29]. This approach can provide cost-effective solutions that bridge geographical and institutional barriers [30]. Mobile health app use for telemedicine is gaining in popularity in developing countries, where medical institutions are often remote and inaccessible [31,32]. Globally, chronic diseases currently account for $60 \%$ of the global disease burden [33]. Importantly, patients with chronic diseases are prone to secondary complications, which can be prevented by strengthening patient education and self-management. Mobile health apps can be used in a variety of environments, enhancing their effectiveness as tools for self-management and monitoring 
[34]. They are widely used in the management of diabetes, hypertension, and asthma [35,36]. Mobile health apps can provide personalized medication adherence reminders and early warnings and improve medication adherence in patients $[37,38]$.

Cluster 4 (yellow cluster) mainly focuses on mobile health apps used in health behavior and health promotion and includes 18 high-frequency keywords, such as intervention, health, physical activity, behavior, risk, weight loss, obesity, nutrition, diet, health promotion, and overweight. With the development of portable wearable devices and smart sensors, mobile health apps can provide self-tracking capabilities. People can track measures of interest such as weight, calories consumed, heart rate, respiratory rate, and exercise status, and can also record how they feel or how they are responding to treatment (eg, side effects). Tracking capabilities of this type can be used by people to promote the adoption of healthful behaviors, such as physical exercise, reasonable diet, and obesity prevention [39-41].

Cluster 5 (purple cluster) mainly focuses on mobile health apps used in disease prevention via the internet and includes 10 high-frequency keywords, such as internet, prevention, trial, smoking cessation, social media, cancer, and human immunodeficiency virus (HIV). The International Telecommunication Union estimates that 4.1 billion people were using the internet at the end of 2019 [42]. The internet can provide anonymity, low intervention costs, and the ability to fulfill effective solutions. Building on these characteristics, internet-based mobile health apps can promote disease prevention to solve health problems. Compared with traditional disease prevention, mobile health apps using social media technology can attract users in a more interactive way, provide convenient health education and rapid internet intervention, and achieve excellent results in HIV, smoking cessation, and cancer [43-45].

\section{Limitations}

Our study is, to our knowledge, the first bibliometric analysis of mobile health app-related publications. Still, there are some limitations to this study. First, there may be language bias because, although we did not place any limits on the language of publications in our study, most WOS publications are in English. Second, the quality of publications in WOS is not uniform. Conducting a weighted analysis of publications based on the assessment of quality was outside the scope of our study; therefore, it is possible that our analysis has given equal attention to publications of differing quality. Finally, the current data for analysis were only extracted from WOS, excluding data extracted from other search engines such as Scopus (Elsevier), PubMed, or Google Scholar (Google LLC). Thus, it is possible that publications appearing only through one of these other search engines have been missed. We plan to address this by exploring ways of combining different data sources in future work.

\section{Conclusions}

Through the bibliometric quantitative analysis and visualization network map of the data extracted from the WOS database, the current study reveals the research status, research trends, hot spots, and coauthorship network of mobile health app research. Mobile health app research is a new and promising field globally, with great potential for improving patient care and promoting health. By comprehensively summarizing the trends in mobile health app research, we expect this work may serve as a guide for facilitating future research directions to advance this field of research further.

\section{Acknowledgments}

This research was supported by the Humanities Social Science Foundation of Ministry of Education (Grant No. 17YJCZH184), the Philosophy and Social Sciences Promotion Project of China Medical University (Grant No. 111-3110118083), and the Health Big Data Research Project of China Medical University (Grant No. 111-HMB201901101).

\section{Conflicts of Interest}

None declared.

\section{Multimedia Appendix 1}

Top 100 keywords and 5 clusters in mobile health app research, 2000-2019. [DOCX File, 22 KB-Multimedia Appendix 1]

\section{References}

1. Zhao J, Freeman B, Li M. Can Mobile Phone Apps Influence People's Health Behavior Change? An Evidence Review. J Med Internet Res 2016 Oct 31;18(11):e287 [FREE Full text] [doi: 10.2196/jmir.5692] [Medline: 27806926]

2. Larson RS. A Path to Better-Quality mHealth Apps. JMIR Mhealth Uhealth 2018 Jul 30;6(7):e10414. [doi: 10.2196/10414]

3. Zion Market Research. Global mHealth Apps Market Will Reach USD 111.1 Billion By 2025: Zion Market Research URL: https://www.globenewswire.com/news-release/2019/01/24/1704860/0/en/

Global-mHealth-Apps-Market-Will-Reach-USD-111-1-Billion-By-2025-Zion-Market-Research.html [accessed 2019-01-24]

4. Martínez-Pérez B, de LTI, López-Coronado M. Mobile health applications for the most prevalent conditions by the World Health Organization: review and analysis. J Med Internet Res 2013 Jun 14;15(6):e120 [FREE Full text] [doi:

10.2196/jmir.2600] [Medline: 23770578] 
5. Guler AT, Waaijer CJF, Palmblad M. Scientific workflows for bibliometrics. Scientometrics 2016 Feb 15;107(2):385-398. [doi: $10.1007 / \mathrm{s} 11192-016-1885-6]$

6. Ahmadvand A, Kavanagh D, Clark M, Drennan J, Nissen L. Trends and Visibility of "Digital Health" as a Keyword in Articles by JMIR Publications in the New Millennium: Bibliographic-Bibliometric Analysis. J Med Internet Res 2019 Dec 19;21(12):e10477 [FREE Full text] [doi: 10.2196/10477] [Medline: 31855190$]$

7. Taj F, Klein MCA, van Halteren A. Digital Health Behavior Change Technology: Bibliometric and Scoping Review of Two Decades of Research. JMIR Mhealth Uhealth 2019 Dec 13;7(12):e13311. [doi: 10.2196/13311]

8. Zou L, Sun L. Global diabetic kidney disease research from 2000 to 2017: A bibliometric analysis. Medicine (Baltimore) 2019 Mar;98(6):e14394 [FREE Full text] [doi: 10.1097/MD.0000000000014394] [Medline: 30732183]

9. Agarwal A, Durairajanayagam D, Tatagari S, Esteves S, Harlev A, Henkel R, et al. Bibliometrics: tracking research impact by selecting the appropriate metrics. Asian J Androl 2016;18(2):296. [doi: 10.4103/1008-682x.171582]

10. Li F, Li M, Guan P, Ma S, Cui L. Mapping Publication Trends and Identifying Hot Spots of Research on Internet Health Information Seeking Behavior: A Quantitative and Co-Word Biclustering Analysis. J Med Internet Res 2015 Mar 25;17(3):e81. [doi: 10.2196/jmir.3326]

11. Cozzens SE, Callon M, Law J, Rip A. Mapping the Dynamics of Science and Technology: Sociology of Science in the Real World. Contemporary Sociology 1988 Nov;17(6):815. [doi: 10.2307/2073618]

12. Zhang C, Yu Q, Fan Q, Duan Z. Research collaboration in health management research communities. BMC Med Inform Decis Mak 2013 Apr 23;13(1). [doi: 10.1186/1472-6947-13-52]

13. Zhang J, Xie J, Hou W, Tu X, Xu J, Song F, et al. Mapping the Knowledge Structure of Research on Patient Adherence: Knowledge Domain Visualization Based Co-Word Analysis and Social Network Analysis. PLoS ONE 2012 Apr 5;7(4):e34497. [doi: 10.1371/journal.pone.0034497]

14. Wang Y, Wang Q, Wei X, Shao J, Zhao J, Zhang Z, et al. Global scientific trends on exosome research during 2007-2016: a bibliometric analysis. Oncotarget 2017 Apr 19;8(29). [doi: 10.18632/oncotarget.17223]

15. Zhao J, Yu G, Cai M, Lei X, Yang Y, Wang Q, et al. Bibliometric analysis of global scientific activity on umbilical cord mesenchymal stem cells: a swiftly expanding and shifting focus. Stem Cell Res Ther 2018 Feb 7;9(1). [doi: 10.1186/s13287-018-0785-5]

16. Miao Y, Xu S, Chen L, Liang G, Pu Y, Yin L. Trends of long noncoding RNA research from 2007 to 2016: a bibliometric analysis. Oncotarget 2017 Oct 10;8(47):83114-83127 [FREE Full text] [doi: 10.18632/oncotarget.20851] [Medline: 29137328]

17. Khan MS, Ullah W, Riaz IB, Bhulani N, Manning WJ, Tridandapani S, et al. Top 100 cited articles in cardiovascular magnetic resonance: a bibliometric analysis. J Cardiovasc Magn Reson 2016 Nov 21;18(1). [doi: 10.1186/s12968-016-0303-9]

18. Romero L, Portillo-Salido E. Trends in Sigma-1 Receptor Research: A 25-Year Bibliometric Analysis. Front. Pharmacol 2019 May 24;10. [doi: 10.3389/fphar.2019.00564]

19. van Eck NJ, Waltman L. Software survey: VOSviewer, a computer program for bibliometric mapping. Scientometrics 2009 Dec 31;84(2):523-538. [doi: 10.1007/s11192-009-0146-3]

20. Eck NJV, Waltman L. How to normalize cooccurrence data? An analysis of some well-known similarity measures. J. Am. Soc. Inf. Sci 2009 Aug;60(8):1635-1651. [doi: 10.1002/asi.21075]

21. Gan J, Cai Q, Galer P, Ma D, Chen X, Huang J, et al. Mapping the knowledge structure and trends of epilepsy genetics over the past decade. Medicine 2019;98(32):e16782. [doi: 10.1097/md.0000000000016782]

22. Schnall R, Rojas M, Bakken S, Brown W, Carballo-Dieguez A, Carry M, et al. A user-centered model for designing consumer mobile health (mHealth) applications (apps). J Biomed Inform 2016 Apr;60:243-251. [doi: 10.1016/j.jbi.2016.02.002] [Medline: 26903153]

23. Martínez-Pérez B, de LTI, López-Coronado M. Privacy and security in mobile health apps: a review and recommendations. J Med Syst 2015 Jan;39(1):181. [doi: 10.1007/s10916-014-0181-3] [Medline: 25486895]

24. Singler K, Roth T, Beck S, Cunningham M, Gosch M. Development and initial evaluation of a point-of-care educational app on medical topics in orthogeriatrics. Arch Orthop Trauma Surg 2015 Dec 8;136(1):65-73. [doi: $10.1007 / \mathrm{s} 00402-015-2366-8]$

25. Vagge A, Wangtiraumnuay N, Pellegrini M, Scotto R, Iester M, Traverso CE. Evaluation of a Free Public Smartphone Application to Detect Leukocoria in High-Risk Children Aged 1 to 6 Years. J Pediatr Ophthalmol Strabismus 2019 Jul 01;56(4):229-232. [doi: 10.3928/01913913-20190516-01]

26. Anthes E. Mental health: There's an app for that. Nature 2016 Apr 07;532(7597):20-23. [doi: 10.1038/532020a] [Medline: 27078548]

27. Donker T, Petrie K, Proudfoot J, Clarke J, Birch M, Christensen H. Smartphones for smarter delivery of mental health programs: a systematic review. J Med Internet Res 2013 Nov 15;15(11):e247 [FREE Full text] [doi: 10.2196/jmir.2791] [Medline: 24240579]

28. Lemey C, Larsen ME, Devylder J, Courtet P, Billot R, Lenca P, et al. Clinicians' Concerns About Mobile Ecological Momentary Assessment Tools Designed for Emerging Psychiatric Problems: Prospective Acceptability Assessment of the MEmind App. J Med Internet Res 2019 Apr 25;21(4):e10111. [doi: 10.2196/10111] 
29. Bashshur RL, Howell JD, Krupinski EA, Harms KM, Bashshur N, Doarn CR. The Empirical Foundations of Telemedicine Interventions in Primary Care. Telemed J E Health 2016 May;22(5):342-375 [FREE Full text] [doi: 10.1089/tmj.2016.0045] [Medline: 27128779]

30. Silva BMC, Rodrigues JJPC, de LTDI, López-Coronado M, Saleem K. Mobile-health: A review of current state in 2015. J Biomed Inform 2015 Aug;56:265-272 [FREE Full text] [doi: 10.1016/j.jbi.2015.06.003] [Medline: 26071682]

31. Déglise C, Suggs LS, Odermatt P. Short Message Service (SMS) Applications for Disease Prevention in Developing Countries. J Med Internet Res 2012 Jan 12;14(1):e3. [doi: 10.2196/jmir.1823]

32. Källander K, Tibenderana JK, Akpogheneta OJ, Strachan DL, Hill Z, ten Asbroek AHA, et al. Mobile Health (mHealth) Approaches and Lessons for Increased Performance and Retention of Community Health Workers in Low- and Middle-Income Countries: A Review. J Med Internet Res 2013 Jan 25;15(1):e17. [doi: 10.2196/jmir.2130] [Medline: 23353680]

33. World Health Organization. World Health Organization. Geneva, Switzerland: Noncommunicable Diseases and Mental Health, World Health Organization; 2002. Innovative care for chronic conditions: building blocks for action URL: https:/ /www.who.int/chp/knowledge/publications/icccglobalreport.pdf?ua=1 [accessed 2020-05-30]

34. Parmanto B, Pramana G, Yu DX, Fairman AD, Dicianno BE, McCue MP. iMHere: A Novel mHealth System for Supporting Self-Care in Management of Complex and Chronic Conditions. JMIR Mhealth Uhealth 2013 Jul 11;1(2):e10 [FREE Full text] [doi: 10.2196/mhealth.2391] [Medline: 25100682]

35. Lum E, Jimenez G, Huang Z, Thai L, Semwal M, Boehm BO, et al. Decision Support and Alerts of Apps for Self-management of Blood Glucose for Type 2 Diabetes. JAMA 2019 Dec 16;321(15):1530-1532. [doi: 10.1001/jama.2019.1644] [Medline: 30990543]

36. Holmen H, Torbjørnsen A, Wahl AK, Jenum AK, Småstuen MC, Arsand E, et al. A Mobile Health Intervention for Self-Management and Lifestyle Change for Persons With Type 2 Diabetes, Part 2: One-Year Results From the Norwegian Randomized Controlled Trial RENEWING HEALTH. JMIR Mhealth Uhealth 2014 Dec;2(4):e57 [FREE Full text] [doi: 10.2196/mhealth.3882] [Medline: 25499872]

37. Zanetti-Yabur A, Rizzo A, Hayde N, Watkins AC, Rocca JP, Graham JA. Exploring the usage of a mobile phone application in transplanted patients to encourage medication compliance and education. The American Journal of Surgery 2017 Oct;214(4):743-747. [doi: 10.1016/j.amjsurg.2017.01.026]

38. Labovitz DL, Shafner L, Reyes GM, Virmani D, Hanina A. Using Artificial Intelligence to Reduce the Risk of Nonadherence in Patients on Anticoagulation Therapy. Stroke 2017 May;48(5):1416-1419. [doi: 10.1161/STROKEAHA.116.016281] [Medline: 28386037]

39. Stavrositu C, Kim J. Self-Persuasion Through Mobile Applications: Exploring Different Routes to Health Behavioral Change. Cyberpsychology, Behavior, and Social Networking 2018 Aug;21(8):516-522. [doi: 10.1089/cyber.2018.0079]

40. Dennison L, Morrison L, Conway G, Yardley L. Opportunities and challenges for smartphone applications in supporting health behavior change: qualitative study. J Med Internet Res 2013 Apr;15(4):e86 [FREE Full text] [doi: 10.2196/jmir.2583] [Medline: 23598614]

41. Martin C, Gilmore L, Apolzan J, Myers C, Thomas D, Redman L. Smartloss: A Personalized Mobile Health Intervention for Weight Management and Health Promotion. JMIR Mhealth Uhealth 2016 Mar 16;4(1):e18 [FREE Full text] [doi: 10.2196/mhealth.5027] [Medline: 26983937]

42. ITUPublications. Measuring digital development: Facts \& figures 2019 URL: https://www.itu.int/en/ITU-D/Statistics/Pages/ facts/default.aspx [accessed 2020-05-31]

43. Schnall R, Mosley JP, Iribarren SJ, Bakken S, Carballo-Diéguez A, Brown IW. Comparison of a User-Centered Design, Self-Management App to Existing mHealth Apps for Persons Living With HIV. JMIR Mhealth Uhealth 2015;3(3):e91 [FREE Full text] [doi: 10.2196/mhealth.4882] [Medline: 26385783]

44. Powell AC, Torous J, Chan S, Raynor GS, Shwarts E, Shanahan M, et al. Interrater Reliability of mHealth App Rating Measures: Analysis of Top Depression and Smoking Cessation Apps. JMIR Mhealth Uhealth 2016;4(1):e15 [FREE Full text] [doi: $10.2196 /$ mhealth.5176] [Medline: $\underline{26863986}$ ]

45. Coughlin S, Thind H, Liu B, Champagne N, Jacobs M, Massey RI. Mobile Phone Apps for Preventing Cancer Through Educational and Behavioral Interventions: State of the Art and Remaining Challenges. JMIR Mhealth Uhealth 2016 May 30;4(2):e69. [doi: 10.2196/mhealth.5361]

\section{Abbreviations \\ HIV: human immunodeficiency virus \\ WOS: Web of Science}


Edited by G Eysenbach; submitted 11.02.20; peer-reviewed by C Kruse, I Moreira; comments to author 10.03.20; revised version received 20.04.20; accepted 26.04.20; published 27.07.20

Please cite as:

Peng C, He M, Cutrona SL, Kiefe CI, Liu F, Wang Z

Theme Trends and Knowledge Structure on Mobile Health Apps: Bibliometric Analysis

JMIR Mhealth Uhealth 2020;8(7):e18212

URL: https://mhealth.jmir.org/2020/7/e18212

doi: $10.2196 / 18212$

PMID: 32716312

(C) Cheng Peng, Miao He, Sarah L Cutrona, Catarina I Kiefe, Feifan Liu, Zhongqing Wang. Originally published in JMIR mHealth and uHealth (http://mhealth.jmir.org), 27.07.2020. This is an open-access article distributed under the terms of the Creative Commons Attribution License (https://creativecommons.org/licenses/by/4.0/), which permits unrestricted use, distribution, and reproduction in any medium, provided the original work, first published in JMIR mHealth and uHealth, is properly cited. The complete bibliographic information, a link to the original publication on http://mhealth.jmir.org/, as well as this copyright and license information must be included. 